\title{
Old Solutions for New Troubles in Complications after Thoracic Endovascular Aortic Repair
}

\author{
German Alberto Fortunato ${ }^{1}$ Guillermo Stöger ${ }^{1}$ Ricardo Gustavo Marenchino ${ }^{1}$ Vadim Kotowicz \\ ${ }^{1}$ Department of Cardiovascular Surgery, Hospital Italiano de Buenos \\ Aires, Buenos Aires, Argentina \\ Thorac Cardiovasc Surg Rep 2017;6:e25-e28. \\ Address for correspondence German Alberto Fortunato, MD, \\ Department of Cardiovascular Surgery, Hospital Italiano de Buenos \\ Aires, Peron 4190, Buenos Aires 1407, Argentina \\ (e-mail: g_fortunato@hotmail.com; \\ german.fortunato@hospitalitaliano.org.ar).
}

\author{
Abstract \\ Keywords \\ - thoracic endovascular \\ aortic repair \\ - extra-anatomical \\ aorto-aortic bypass \\ - aortic bypass graft \\ - complications
}

Background The authors present two cases with type B aortic dissection initially treated by endovascular stent graft who developed aortic complications posttreatment and required surgical treatment.

Case Description A 50-year-old woman and a 65-year-old man underwent endovascular treatment for thoracic aortic aneurysm associated with type B dissection and both of them evolved with endoleak type 1. The first case was related to aortobronchial fistula, and the second one was associated with ascending aortic aneurysm. An extraanatomical ascending aorta-supraceliac aorta bypass grafting was decided due to the persistent leak.

Conclusion Surgery is an excellent choice for complex complications after thoracic endovascular aortic repair with previous failed attempts of endovascular resolution.

\section{Introduction}

Type B aortic dissection (TBAD) is a potentially life-threatening disease. A complicated TBAD requires invasive treatment immediately.

Around 10 to $40 \%$ of these patients develop complications that require new interventions. ${ }^{1}$ Although the replacement of the descending aorta is the technique of choice preferred in this subgroup, in patients with preexisting conditions (clinical situation, anatomical problems, comorbidities, etc.) the exclusion of the descending aorta with an extra-anatomic aortoaortic bypass grafting (ascending aorta to abdominal aorta) can simplify the procedure and solve the pathology.

We present two cases with TBAD initially treated by endovascular stent graft who developed aortic complications that required surgical treatment.

\section{Case Presentation and Surgical Approach}

\section{Case 1}

A 50-year-old female patient, treated with stent graft for complicated TBAD 6 months ago, is brought to the emergency room for massive hemoptysis associated with hypo-

received

June 30,2017

accepted after revision

July 13, 2017 volemic shock. The computed tomography scan shows enlargement of the aorta's isthmus with endoleak type I, compression of the left main bronchus, and aortobronchial fistula (-Fig. 1: Case 1). The ascending aorta appears normal. The patient is in circulatory shock prior to entering the operating room.

A selective intubation is performed. The intubation is carried out with sternolaparotomy (Mercedez Benz), cardiopulmonary bypass with double-arterial (right axillary/right femoral) cannulation (Cannula EOPA TM Arterial Cannulae, Medtronic, United States), and venous cannula (Edwards Lifesciences, Irvine, CA) in the right atrium. During deep hypothermia circulatory arrest (DHCA) the dissection is completed, the ascending aorta is clamped, and cardioplegia infused. Next, the supraceliac aorta is clamped, and femoral cannula performs the visceral protection. The distal end of the descending aorta is closed, and it is excluded from the circulation, and the ascending aorta-supraceliac aorta bypass is constructed (end-to-end) with a Dacron graft \# 20 (Hemagard, Maquet, Germany) (-Fig. 2A).

At $18^{\circ} \mathrm{C}$ the innominate artery is clamped, preserving axillary and visceral perfusion. The aortic arch is opened,
License terms

Stuttgart · New York

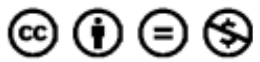



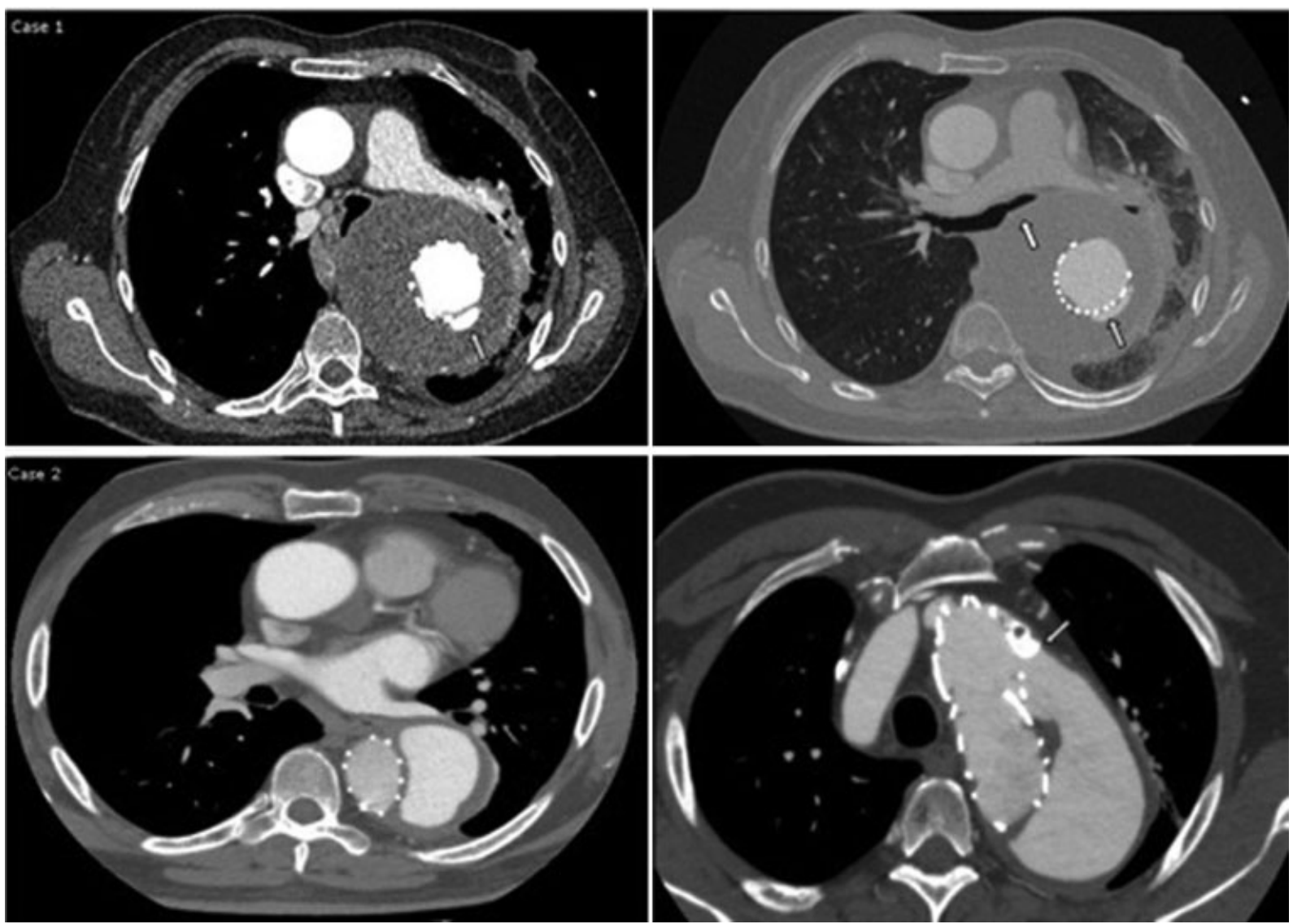

Fig. 1 Case 1: Preoperative CT scan showing proximal endoleak (yellow arrow) and contact of the aneurysmal sac with airway. Case 2 : Aneurysm of ascending aorta and proximal endoleak (yellow arrow).

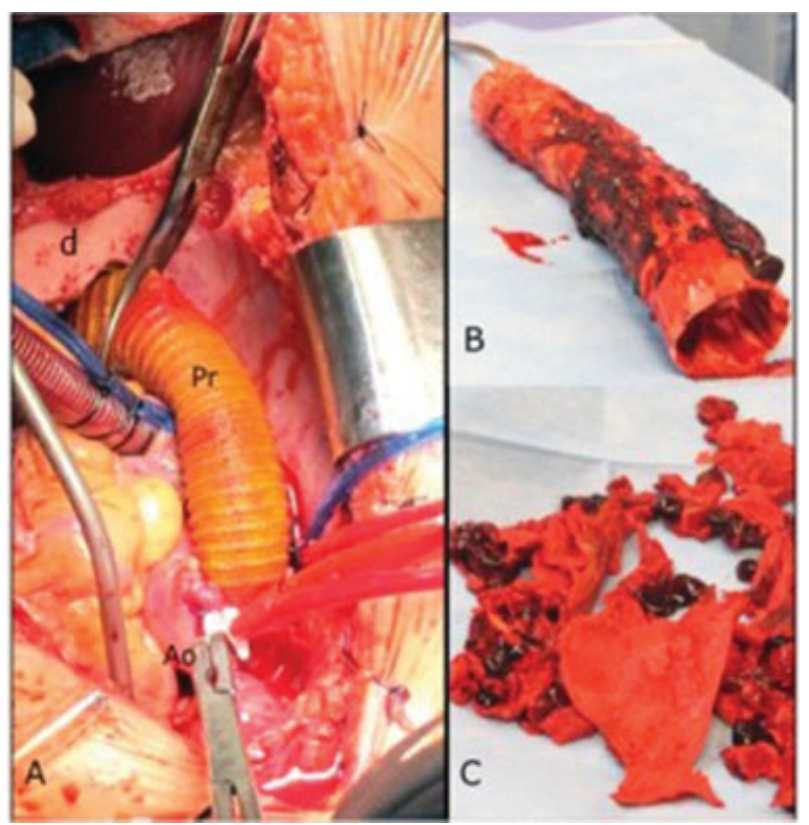

Fig. 2 (A) Extra anatomical aorto-aortic bypass from ascending aorta (Ao) to supraceliac aorta with dacron graft (pr) through the diaphragm (d). (B) Stent removed. (C) Thoracic aortic resection and removal of clots. and the stent graft is extracted ( $\mathbf{- F i g . ~ 2 B ) . ~ T h e ~ d i s t a l ~ a r c h ~ i s ~}$ closed with a Dacron patch. The proximal anastomosis of the ascending aorta-abdominal aorta (end-to-side) is completed. Then, the airway is decompressed by removing clots from the descending aorta ( - Fig. 2C) confirmed by bronchoscopy. Several days after surgery, the patient evolves with sepsis, abscess of the residual aortic sac, which is communicated with the airway, requiring left pneumonectomy. The patient was discharged after 60 days of hospitalization. No neurological complication was observed.

\section{Case 2}

A 65-year-old male patient, obese, hypertensive, chronic obstructive pulmonary disease (COPD), diabetes, underwent endovascular treatment for type B dissection. Patient evolves with sac enlargement and type 1 endoleak (-Fig. 1: Case 2). The patient presents the history of two endovascular treatment with previous unsuccessful stent placement. The proximal descending aorta measured $80 \times 90 \mathrm{~mm}$, ascending aorta $50 \mathrm{~mm}$, abdominal aorta $33 \mathrm{~mm}$, and it presented a flap dissection. It was decided to avoid a thoracotomy based on risk factors for adverse events related to the incision in the patient (obesity and COPD).

The approach was similar to that described earlier in terms of cannulation and surgery strategy. In this case, due 


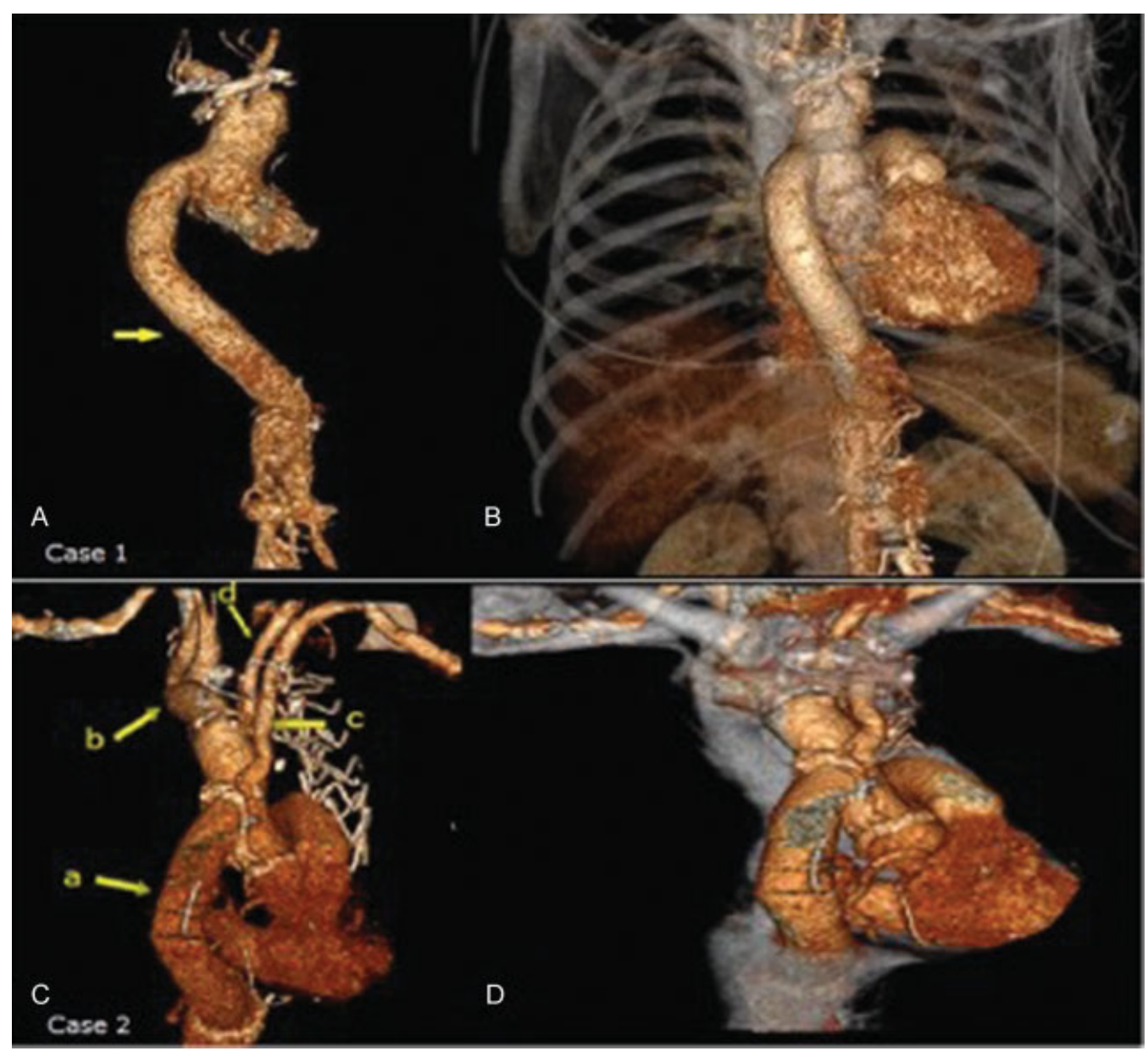

Fig. 3 Case 1: Postoperative 3D recostruction. Extra anatomical aorto-aortic bypass with dacron graft (yellow arrow). Case 2: Postoperative 3D recostruction showing (a) aorto-aortic bypass, (b) brachiocephalic artery, (c) left subclavian bypass, (d) left carotid artery.

to the necessity to replace ascending aorta and aortic arch, we infuse cardioplegia after clamp, and the proximal anastomosis was drawn in sinotubular union with a Dacron graft \# 28 (Hemagard). At $18^{\circ} \mathrm{C}$, the supraceliac aorta is clamped. Visceral perfusion is maintained by the femoral cannula, and the brain by the brachiocephalic artery. Ascending aorta and arch were replaced, and after that, the distal anastomosis of the Dacron graft previously sutured to the aortic root anastomosed to an island containing brachiocephalic artery and left carotid artery. The left subclavian artery is reinserted separately with a Dacron graft \# 8 (Intergard, Maquet).

During rewarming, the proximal and distal ends of the descending aorta are closed. The supraceliac aorta is perfused by an extra-anatomical aorto-aortic bypass (end-toend) with a Dacron graft \# 26 (Hemagard). The patient evolves without intercurrences, and is discharged after 7 days of hospitalization.

No paraplegia was observed in any of the cases.

\section{Discussion}

The incidence of complications requiring surgical solve postthoracic endovascular aortic repair (TEVAR) ranges between 2.2 and $7.2 \%{ }^{2,3}$ Aortobronchial fistula is a rare complication
$(<1 \%)$ according to the current trial. ${ }^{4}$ Treatment should be radical in the lung (lobectomy, pneumonectomy), as well as in the aorta (stent removal, replacement of the aorta, washing, and removal of mediastinal clots). ${ }^{5}$ In the first case, it was decided an extra-anatomical resolution with a patient in shock, with the aim of a quick defunctionalizing of the descending aorta, decompressing the airway, and waiting for the resolution of the bronchial fistula (-Fig. 3).

Having used double-arterial cannulation (axillary and femoral) allowed us to keep visceral and cerebral circulation throughout the procedure. The use of DHCA is not mandatory; however, it was done to favor both the spinal and cerebral protection.

We consider that this resolution may be useful in selected patients and special situations. ${ }^{6}$

Although the endovascular treatment is the first choice in TBAD complicated, this is not exempt from late complications. Endovascular route can not always solve such complications.

\section{Conclusion}

Surgery is an excellent choice for complex complications after TEVAR with previous failed attempts of endovascular 
resolution, representing a definitive solution to endoleak, preventing the recurrence of the same.

\section{Conflict of Interest}

The authors have no conflicts of interest relevant to this publication.

\section{References}

1 Eggebrecht $\mathrm{H}$, Nienaber CA, Neuhäuser $\mathrm{M}$, et al. Endovascular stent-graft placement in aortic dissection: a meta-analysis. Eur Heart J 2006;27(04):489-498

2 Canaud L, Alric P, Gandet T, Albat B, Marty-Ané C, Berthet JP. Surgical conversion after thoracic endovascular aortic repair. J Thorac Cardiovasc Surg 2011;142(05):1027-1031
3 Dumfarth J, Michel M, Schmidli J, et al. Mechanisms of failure and outcome of secondary surgical interventions after thoracic endovascular aortic repair (TEVAR). Ann Thorac Surg 2011;91 (04):1141-1146

4 Czerny M, Reser D, Eggebrecht H, et al. Aorto-bronchial and aortopulmonary fistulation after thoracic endovascular aortic repair: an analysis from the European Registry of Endovascular Aortic Repair Complications. Eur J Cardiothorac Surg 2015;48(02):252-257

5 Czerny M, von Allmen R, Opfermann P, et al. Self-made pericardial tube graft: a new surgical concept for treatment of graft infections after thoracic and abdominal aortic procedures. Ann Thorac Surg 2011;92(05):1657-1662

6 Girdauskas E, Falk V, Kuntze T, et al. Secondary surgical procedures after endovascular stent grafting of the thoracic aorta: successful approaches to a challenging clinical problem. J Thorac Cardiovasc Surg 2008;136(05):1289-1294 